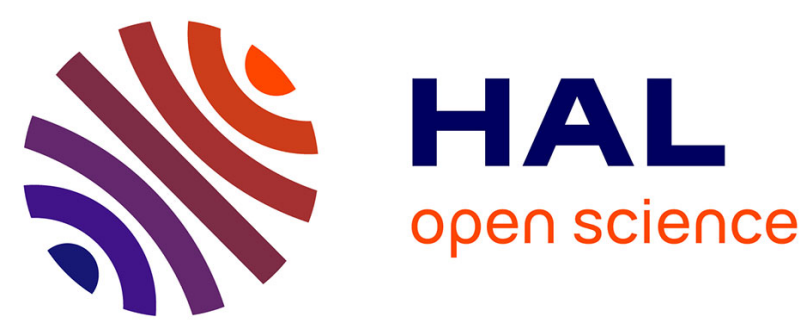

\title{
Future sea level change under CMIP5 and CMIP6 scenarios from the Greenland and Antarctic ice sheets
}

Antony Payne, Sophie Nowicki, Ayako Abe-ouchi, Cécile Agosta, Patrick

Alexander, Torsten Albrecht, Xylar Asay-davis, Andy Aschwanden, Alice

Barthel, Thomas Bracegirdle, et al.

\section{To cite this version:}

Antony Payne, Sophie Nowicki, Ayako Abe-ouchi, Cécile Agosta, Patrick Alexander, et al.. Future sea level change under CMIP5 and CMIP6 scenarios from the Greenland and Antarctic ice sheets. Geophysical Research Letters, 2021, 48 (16), pp.e2020GL091741. 10.1029/2020GL091741 . hal03228366

\section{HAL Id: hal-03228366 https://hal.science/hal-03228366}

Submitted on 14 Jun 2021

HAL is a multi-disciplinary open access archive for the deposit and dissemination of scientific research documents, whether they are published or not. The documents may come from teaching and research institutions in France or abroad, or from public or private research centers.
L'archive ouverte pluridisciplinaire HAL, est destinée au dépôt et à la diffusion de documents scientifiques de niveau recherche, publiés ou non, émanant des établissements d'enseignement et de recherche français ou étrangers, des laboratoires publics ou privés. 


\section{Future sea level change under CMIP5 and CMIP6 scenarios from the Greenland and Antarctic ice sheets}

Antony J. Payne ${ }^{1}$, Sophie Nowicki ${ }^{2,3}$, Ayako Abe-Ouchi ${ }^{4}$, Cécile Agosta ${ }^{5}$, Patrick Alexander ${ }^{6,7}$, Torsten Albrecht ${ }^{8}$, Xylar Asay-Davis ${ }^{9}$, Andy Aschwanden ${ }^{10}$, Alice Barthel ${ }^{9}$, Thomas J. Bracegirdle ${ }^{11}$, Reinhard Calov ${ }^{8}$, Christopher Chambers ${ }^{12}$, Youngmin Choi ${ }^{13}$, Richard Cullather ${ }^{2}$, Joshua Cuzzone ${ }^{14}$, Christophe Dumas ${ }^{5}$, Tamsin L. Edwards ${ }^{15}$, Denis Felikson ${ }^{2,16}$, Xavier Fettweis ${ }^{17}$, Benjamin K. Galton-Fenzi ${ }^{18,19}$, Heiko Goelzer ${ }^{20,21,22}$, Rupert Gladstone ${ }^{23}$, Nicholas R. Golledge ${ }^{24}$, Jonathan M. Gregory ${ }^{25,26}$, Ralf Greve ${ }^{11,27}$, Tore Hattermann ${ }^{28,29}$, Matthew J. Hoffman ${ }^{9}$, Angelika Humbert ${ }^{30,31}$, Philippe Huybrechts ${ }^{32}$, Nicolas C. Jourdain ${ }^{33}$, Thomas Kleiner ${ }^{30}$, Peter Kuipers Munneke ${ }^{20}$, Eric Larour ${ }^{14}$, Sebastien Le clec'h ${ }^{32}$, Victoria Lee ${ }^{1}$, Gunter Leguy ${ }^{34}$, William H. Lipscomb ${ }^{34}$, Christopher M. Little ${ }^{35}$, Daniel P. Lowry ${ }^{36}$, Mathieu Morlighem ${ }^{13}$, Isabel Nias ${ }^{2,37}$, Frank Pattyn ${ }^{21}$, Tyler Pelle ${ }^{13}$, Stephen F. Price ${ }^{9}$, Aurélien Quiquet ${ }^{5}$, Ronja Reese ${ }^{8}$, Martin Rückamp ${ }^{30}$, Nicole-Jeanne Schlegel ${ }^{14}$, Hélène Seroussi ${ }^{14}$, Andrew Shepherd ${ }^{38}$, Erika Simon ${ }^{2}$, Donald Slater ${ }^{39}$, Robin S. Smith ${ }^{25}$, Fiammetta Straneo ${ }^{39}$, Sainan Sun ${ }^{21}$, Lev Tarasov ${ }^{40}$, Luke D. Trusel ${ }^{41}$, Jonas Van Breedam ${ }^{32}$, Roderik van de Wal ${ }^{20,42}$, Michiel van den Broeke ${ }^{20}$, Ricarda Winkelmann ${ }^{8,43}$, Chen Zhao ${ }^{19}$, Tong Zhang ${ }^{9}$, Thomas Zwinger ${ }^{44}$

${ }^{1}$ Centre for Polar Observation and Modelling, University of Bristol, Bristol, UK

${ }^{2}$ Cryospheric Sciences Laboratory, Code 615, NASA Goddard Space Flight Center, Greenbelt, MD 20771, USA

${ }^{3}$ Geology Department and RENEW Institute, University at Buffalo, Buffalo, NY, USA

${ }^{4}$ Atmosphere and Ocean Research Institute, The University of Tokyo, Kashiwa-shi, Japan

${ }^{5}$ Laboratoire des Sciences du Climat et de lEnvironnement, LSCE-IPSL, CEA-CNRS-UVSQ, Université Paris-Saclay, Gif-sur-Yvette, France

${ }^{6}$ Lamont-Doherty Earth Observatory, Columbia University, Palisades, NY, USA ${ }^{7}$ NASA Goddard Institute for Space Studies, New York, NY, USA

${ }^{8}$ Potsdam Institute for Climate Impact Research (PIK), Member of the Leibniz Association, Potsdam,

$$
\text { Germany }
$$

${ }^{9}$ Theoretical Division, Los Alamos National Laboratory, Los Alamos, NM, USA

${ }^{10}$ Geophysical Institute, University of Alaska, Fairbanks, AK 99775, USA

${ }^{11}$ British Antarctic Survey, Cambridge, UK

${ }^{12}$ Institute of Low Temperature Science, Hokkaido University, Sapporo, Japan

${ }^{13}$ Department of Earth System Science, University of California Irvine, Irvine, USA

${ }^{14}$ Jet Propulsion Laboratory, California Institute of Technology, Pasadena, CA, USA

${ }_{15}$ Department of Geography, Kings College London, London, UK

${ }^{16}$ Universities Space Research Association, Goddard Earth Sciences Technology and Research Studies and Investigations, Columbia, MD 21044, USA

${ }^{17}$ Laboratory of Climatology, Department of Geography, University of Liége, Liége, Belgium 18 Australian Antarctic Division, Kingston, Tasmania, Australia

${ }^{19}$ Australian Antarctic Program Partnership, Institute for Marine and Antarctic Studies, University of Tasmania, Hobart, Tasmania, Australia

${ }^{20}$ Institute for Marine and Atmospheric research Utrecht, Utrecht University, Utrecht, the Netherlands

${ }^{21}$ Laboratoire de Glaciologie, Université Libre de Bruxelles, Brussels, Belgium

${ }^{22}$ NORCE Norwegian Research Centre, Bjerknes Centre for Climate Research, Bergen, Norway ${ }^{23}$ Arctic Centre, University of Lapland, Finland

${ }^{24}$ Antarctic Research Centre, Victoria University of Wellington, New Zealand

${ }^{25}$ National Center for Atmospheric Science, University of Reading, Reading, UK ${ }^{26}$ Met Office, Hadley Centre, Exeter, UK ${ }^{27}$ Arctic Research Center, Hokkaido University, Sapporo, Japan ${ }_{28}$ Norwegian Polar Institute, Troms $\varnothing$, Norway

${ }^{29}$ Department of Physics and Technology, The Arctic University University of Troms $\varnothing$, Norway

${ }^{30}$ Alfred Wegener Institute for Polar and Marine Research, Bremerhaven, Germany

${ }^{31}$ Department of Geoscience, University of Bremen, Bremen, Germany

${ }^{32}$ Earth System Science and Departement Geografie, Vrije Universiteit Brussel, Brussels, Belgium

${ }^{33}$ Univ. Grenoble Alpes/CNRS/IRD/G-INP. Institut des Géosciences de l'Environnement, France

${ }^{34}$ Climate and Global Dynamics Laboratory, National Center for Atmospheric Research, Boulder, CO, USA

35 Atmospheric and Environmental Research, Inc, Lexington, Massachusetts, USA ${ }^{36}$ GNS Science, Lower Hutt, New Zealand

${ }^{37}$ School of Environmental Sciences, University of Liverpool, Liverpool, UK ${ }^{38}$ Centre for Polar Observation and Modelling, University of Leeds, LS2 9JT, UK

This article has been accepted for publication and ${ }^{-1}$ undergone full peer review but has not been through the copyediting, typesetting, pagination and proofreading process, which may lead to differences between this version and the Version of Record. Please cite this article as doi: 10.1029/2020GL091741. 


\begin{abstract}
${ }^{39}$ Scripps Institution of Oceanography, University of California San Diego, La Jolla, CA, USA
${ }^{40}$ Dept of Physics and Physical Oceanography, Memorial University of Newfoundland, Canada

${ }^{41}$ Department of Geography, Pennsylvania State University, University Park, PA, USA

${ }^{42}$ Geosciences, Physical Geography, Utrecht University, Utrecht, The Netherlands

${ }^{43}$ Department of Physics and Astronomy, University of Potsdam, Potsdam, Germany

${ }^{44}$ CSC-IT Center for Science, Espoo, Finland
\end{abstract}

\title{
Key Points:
}

- We compare results from an ice sheet model inter-comparison forced using CMIP6 and CMIP5 climate projections

- Projected sea level at 2100 is higher for Greenland under CMIP6 scenarios than CMIP5, but similar for Antarctica under both scenarios

- CMIP6 warmer climate results in increased Greenland surface melt while increased snowfall mitigates loss from ocean warming for Antarctica

Corresponding author: Tony Payne and Sophie Nowicki, a.j.payne@bristol.ac.uk sophien@buffalo.edu 


\begin{abstract}
Projections of the sea level contribution from the Greenland and Antarctic ice sheets rely on atmospheric and oceanic drivers obtained from climate models. The Earth System Models participating in the Coupled Model Intercomparison Project phase 6 (CMIP6) generally project greater future warming compared with the previous CMIP5 effort. Here we use four CMIP6 models and a selection of CMIP5 models to force multiple ice sheet models as part of the Ice Sheet Model Intercomparison Project for CMIP6 (ISMIP6). We find that the projected sea level contribution at 2100 from the ice sheet model ensemble under the CMIP6 scenarios falls within the CMIP5 range for the Antarctic ice sheet but is significantly increased for Greenland. Warmer atmosphere in CMIP6 models results in higher Greenland mass loss due to surface melt. For Antarctica, CMIP6 forcing is similar to CMIP5 and mass gain from increased snowfall counteracts increased loss due to ocean warming.
\end{abstract}

\title{
Plain Language Summary
}

The melting of the Greenland and Antarctic ice sheets will result in higher sea level in the future. How sea level will change depends in part on how the atmosphere and ocean warm and how this affects the ice sheets. We use multiple ice sheet models to estimate possible future sea levels under climate scenarios from the models participating in the new Coupled Model Intercomparison Project phase 6 (CMIP6), which generally indicate a warmer world that the previous effort (CMIP5). Our results show that the possible future sea level change due Antarctica is similar for CMIP5 and CMIP6, but the warmer atmosphere in CMIP6 models leads to higher sea-level contributions from Greenland by the end of the century.

\section{Introduction}

The overall aim of this paper is to assess whether the stronger future warming shown by many CMIP6 models (Forster et al., 2019; Meehl et al., 2020) compared with CMIP5 has a significant impact on future Global Mean Sea Level Rise (GMLSR). We compare projections for the sea-level contribution of the Greenland and Antarctic ice sheets (GrIS and AIS) under climate forcing from a small group of models from the CMIP6 ensemble (Eyring et al., 2016) with that of models using forcing from the CMIP5 model ensemble (Taylor et al., 2012). Goelzer et al. (2020b) and Seroussi et al. (2020) present detailed analyses of the latter set of experiments for GrIS and AIS, respectively. In both cases, a great deal of attention was paid to sampling the CMIP5 ensemble effectively, so that the CMIP5 models used to provide climate forcing both represented the presentday climate of the ice sheets well and sampled the range of future projections of the overall ensemble. Details of this procedure can be found in Barthel et al. (2020).

Global warming as manifested in regional atmospheric and oceanic change can impact the ice sheet mass budget, and hence contribution to GMSLR, in a number of ways. Warming of the atmosphere over the ice sheet promotes increased melt from snow and ice surfaces leading to increased mass loss in the form of runoff to the oceans. It may also be associated with increased precipitation because of the increased moisture-carrying capacity of warmer air. The relationship between global warming and the warmth of Polar ocean water masses impinging on the ice sheets is likely to be more complex. The warming of these water masses is expected to increase GMSLR by increasing mass loss from the marine-terminating outlet glaciers of the GrIS, and by processes associated with Marine Ice Sheet Instability (Schoof, 2007) for the AIS. An additional complexity for GrIS is that marine mass loss is partly controlled by freshwater fluxes from the surface melt (Slater et al., 2019). Finally, Marine Ice Sheet Instability could also be triggered by atmospheric warming leading to the fracture and collapse of floating ice shelves (Trusel et al., 2015). This process may in turn lead to the subsequent rapid retreat of the exposed 
marine ice cliffs (DeConto \& Pollard, 2016). In summary, the range and complexity of the ways in which climate affects ice-sheet mass budget suggests that the greater global warming found in CMIP6 models may not necessarily lead to increased GMSLR.

\section{The CMIP6 ensemble}

We compare a small ensemble of four Earth System Models (ESMs) submitted to the CMIP6 exercise. These models are UKESM1-0-LL, CESM2, CNRM-CM6-1 and CNRMESM2-1, which were the only ones available for descaling at the time. Because the sample is small and based on availability only, it is important to understand the difference between the selected models and the larger CMIP6 model ensemble. Effective Climate Sensitivity (ECS)(IPCC, 2013) is a convenient measure of this. ECS estimates the global mean temperature response to doubled atmospheric carbon dioxide concentration (Flato et al., 2013). The four selected models all have ECS at the upper end of the CMIP6 ensemble (CESM2, CNRM-CM6-1, CNRM-ESM2-1 and UKESM1-0-LL have ECS of 5.2, 4.8, 4.8 and $5.3{ }^{\circ} \mathrm{C}$, respectively). Roughly half of the CMIP6 ensemble has an ECS of between 4.6 and $5.6{ }^{\circ} \mathrm{C}$, while there is a second similarly-sized group with markedly lower ECS in the range 2.3 to $3.2^{\circ} \mathrm{C}$ (Meehl et al., 2020). In contrast, the CMIP5 ensemble exhibited a fairly continuous range of ECS between 2.1 and $4.7^{\circ} \mathrm{C}$ (Flato et al., 2013). The CMIP5 models used in Goelzer et al. (2020b) and Seroussi et al. (2020) were typically drawn from the upper end of this distribution (e.g., MIROC-ESM, HadGEM2-ES, CSIRO-Mk3-6-0 and IPSL-CM5A-LR with ECS of 4.7, 4.6, 4.1 and $4.1{ }^{\circ} \mathrm{C}$, respectively) or lay close to the median (e.g., CCSM4, NorESM1-M and MIROC5 with ECS of 2.9, 2.8 and $2.7^{\circ} \mathrm{C}$, respectively).

Summaries of the atmospheric and ocean forcing for the two ice sheets are shown in Figures 1 and 2, respectively. Surface warming exhibited over the AIS in CMIP6 lies at or above the high end of the CMIP5 range. A similar pattern is evident in projected changes in Surface Mass Balance (SMB, the annual difference between mass addition, such as snowfall and refrozen rainfall, and mass loss, such as melt and subsequent runoff) over the ice sheet. Neither quantity is, however, significantly higher than the CMIP5 range. For GrIS, SMB was derived by forcing the MAR regional climate model of Greenland (Fettweis et al., 2013) with CMIP6-derived boundary conditions. In this case, the CMIP6forced SMB is significantly more negative (i.e., higher GMSLR rise) than is the case for CMIP5 forcing. Indeed, all four SSP585 ESMs fall outside the CMIP5 range and, by 2100, anomalies from UKESM1-0-LL and CESM2 approach twice that of largest CMIP5 ESM. The oceanic forcing of the AIS is described in detail by Jourdain et al. (2020) and for the GrIS by Slater et al. (2020). The thermal forcing derived from the CMIP6 models for both ice sheets lies within the range of the CMIP5 models with the exception of UKESM10-LL SSP585, which is occasionally higher. In many cases, the forcing lies towards the centre of the CMIP5 range despite the higher ECS of the CMIP6 models. As would be expected thermal forcing from CNRM-CM6-1 SSP126 is less than that from CNRM-CM61 SSP585, however the difference is similar to the difference between the four SSP585 models. 

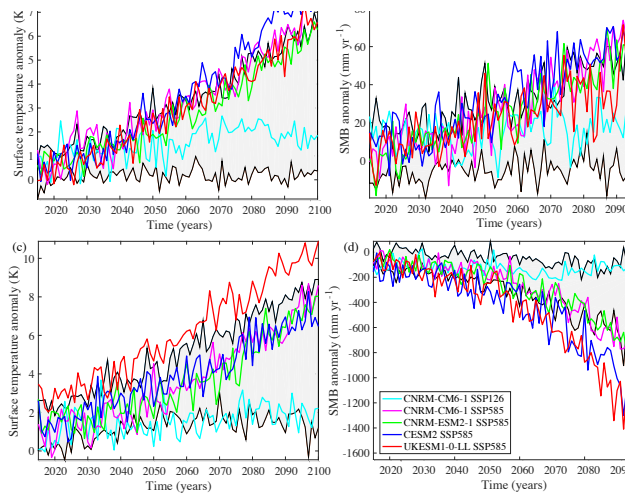

Figure 1. Atmospheric forcing used in CMIP6-forced experiments. (a) and (b) mean annual surface air temperature and Surface Mass Balance (SMB) anomalies over AIS. (c) and (d) mean annual surface air temperature and SMB anomaly for GrIS. Individual CMIP6 experiments are as shown as coloured lines (legend in panel $(\mathrm{d})$ ). Grey shading reflects range of CMIP5 forcing encompassed by all of the CMIP5 experiments used by ISMIP6 (i.e., highest and lowest CMIP5 forcing for each year). 

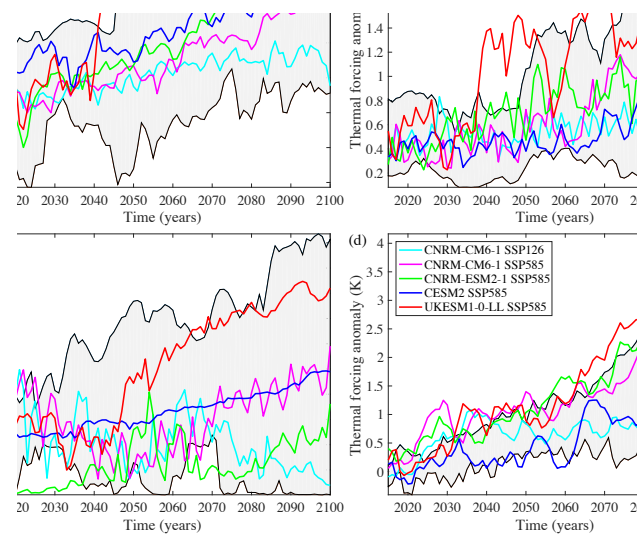

Figure 2. Ocean thermal forcing used in CMIP6-forced experiments for AIS sectors (a) Pine Island and Thwaites Glaciers, (b) Filchner-Ronne ice shelf, (c) Ross ice shelf and (d) for GrIS. Individual CMIP6 experiments are as shown as coloured lines (legend in panel (d)). Grey shading reflects range of CMIP5 forcing encompassed by all of the CMIP5 experiments used by ISMIP6 (i.e., highest and lowest CMIP5 forcing for each year). 
Table 1. Overview of experiments and modelling groups participating in the CMIP6-forced exercise for AIS. Please refer to Seroussi et al. (2020) for model and group details. Symbols are those used in Figure 3.

\begin{tabular}{llccc}
\hline Group & Model & Open & Standard & Symbol \\
\hline AWI & PISM & $1-5$ & $1-5$ & $\circ$ \\
ILTS_PIK & SICOPOLIS & & $1-5$ & $\triangleleft$ \\
JPL & ISSM & & $1-5$ & $\triangleright$ \\
NCAR & CISM & $1-5$ & $1-5$ & $\triangle$ \\
LSCE & GRISLI & & $1-5$ & $\square$ \\
UCIJPL & ISSM & & $1-5$ & $\nabla$ \\
VUB & AISMPALEO & & $1-3$ & $\diamond$ \\
\hline & Total & 2 & 7 & \\
\hline
\end{tabular}

\section{Summary of ISMIP6 experimental procedure}

The procedures used to convert the climate information summarised in Figures 1 and 2 into forcing imposed on ice sheet models are summarised in a series of papers for Antarctic ocean (Jourdain et al., 2020; Favier et al., 2019), Greenland ocean (Slater et al., 2019, 2020) and Greenland atmosphere (Fettweis et al., 2013; Goelzer et al., 2020a). Details of the experimental protocols employed can be found in Nowicki et al. (2016) and Nowicki et al. (2020) and employed a carefully chosen sub-sample of six CMIP5 models for each ice sheet.

These protocols were primarily employed by ice sheet modelling groups to generate projections using forcing from the CMIP5 ensemble, which are reported in Goelzer et al. (2020b) for GrIS and Seroussi et al. (2020) for AIS, however groups also conducted experiments using forcing from the CMIP6 ensemble as summarised in Tables 1 and 2. Both tables refer to experiments using the following numbering: 1) The CNRM-CM61 model run with scenario SSP585 (roughly equivalent to RCP8.5 of CMIP5), 2) CNRMCM6-1 with SSP126 (roughly equivalent to RCP2.6 of CMIP5), and SSP585 with 3) UKESM10-LL, 4) CESM2, 5) CNRM-ESM2-1. Within the ISMIP6 design, experiments could be performed under 'standard' or 'open' configurations (see Nowicki et al., 2020). The former refers to the full implementation of ISMIP6 protocols for converting climate forcing into the mass fluxes experienced by the ice sheets, while in the latter individual groups used their own previously existing methods to do this.

\section{GMSLR projections}

Figure 3 shows projections for the AIS from the seven participating ice sheet models for each CMIP6-forced experiment along with ranges from the equivalent CMIP5-forced experiments (Seroussi et al., 2020). Figure $3 \mathrm{~b}$ to d compares these projections with ranges derived for the CMIP5 ensemble at 2100. The equivalent ranges for the whole AIS are -14 to $155 \mathrm{~mm}$ for RCP2.6, and -76 to $300 \mathrm{~mm}$ for RCP8.5. The regional contributions from West and East AIS are within or below the ranges reported for CMIP5 forcing. In many cases, they sit in the lower half of this range. This, however, is likely to reflect the high GMSLR associated with one ESM in CMIP5 ensemble of six (HadGEM2-ES), whose projected GMSLR was typically much higher (roughly twice that of the other ESMs for West AIS and positive rather than negative for East AIS). The projected GMSLR for all three AIS regions for CMIP6 and CMIP5 is very compatible if HadGEM2-ES is excluded from the latter. 
Table 2. Overview of experiments and modelling groups participating in the CMIP6-forced exercise for GrIS. Please refer to Goelzer et al. (2020b) for model and group details. Symbols are those used in Figure 4. 'f' refers to filled symbol.

\begin{tabular}{llccc}
\hline Group & Model & Open & Standard & Symbol \\
\hline AWI & ISSM1 & & $1-5$ & $\circ$ \\
AWI & ISSM2 & & $1-5$ & $\triangleleft$ \\
AWI & ISSM3 & $1-5$ & $\triangleright$ \\
BGC & BISICLES & $1-3$ & & $*$ \\
GSFC & ISSM & & $1-2$ & $\square$ \\
ILTS_PIK & SICOPOLIS1 & & $1-5$ & $\triangle$ \\
ILTS_PIK & SICOPOLIS2 & & $1-5$ & $\nabla$ \\
IMAU & IMAUICE2 & & $1-3,5$ & $\diamond$ \\
JPL & ISSM & & $1-5$ & $\circ \mathrm{f}$ \\
JPL & ISSMPALEO & & $1-3,5$ & $\triangleleft \mathrm{f}$ \\
LSCE & GRISLI & & $1-5$ & $\triangleright \mathrm{f}$ \\
NCAR & CISM & & $1-5$ & $\square \mathrm{f}$ \\
UAF & PISM1 & & $1-3,5$ & $\triangle \mathrm{f}$ \\
UAF & PISM2 & $1-3,5$ & & $\nabla \mathrm{f}$ \\
UCIJPL & ISSM1 & & $1-3$ & $\diamond \mathrm{f}$ \\
VUB & GISM & & $1-5$ & + \\
\hline Total & & 2 & 14 & \\
\hline
\end{tabular}

Comparing projections for SSP126 (one ESM only) and SSP585 (four ESMs) suggests that there is little impact of emission scenario on projected GMSLR for AIS. This is, again, most likely to be related to the contrasting impacts for global warming on the ice sheet's mass budget through increases in both mass loss by ice-sheet discharge and gain by snow accumulation.

The relationship between forcing and GMSLR for each CMIP6 ESM is complicated. For instance, ocean thermal forcing (Figure 2), air temperature anomalies (Figure 1) tend to be larger for UKESM1-0-LL; however, this is not reflected in their projected GMSLR. This is most likely to be associated with the compensatory effect of increased precipitation (Figure 1) in these ESMs. 

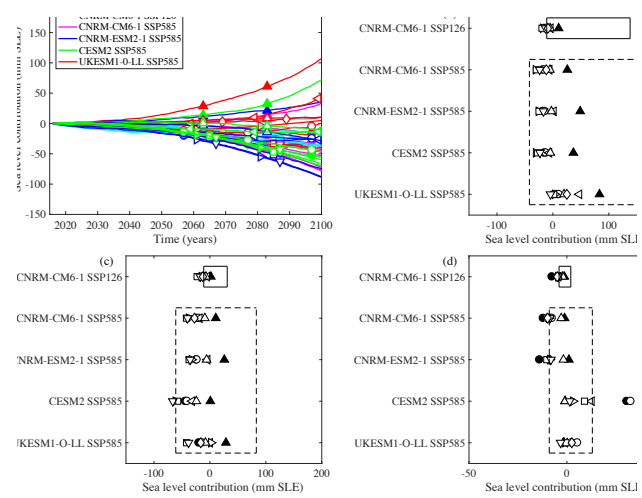

Figure 3. GMSLR contribution from the AIS to 2100. (a) Time series of contribution between 2015 and 2100 (in mm) for whole ice sheet as a function of ice sheet model (symbol) and experiment (see legend). Contribution at 2100 for (b) West AIS, (c) East AIS and (d) Antarctic Peninsula. Symbols refer to ice sheet models and are given in Table 1. Filled symbols refer to 'open' experiments and unfilled for 'standard'. Boxes in panels (b) to (d) refer to ranges from equivalent CMIP5-forced experiments (see Seroussi et al. (2020)). 


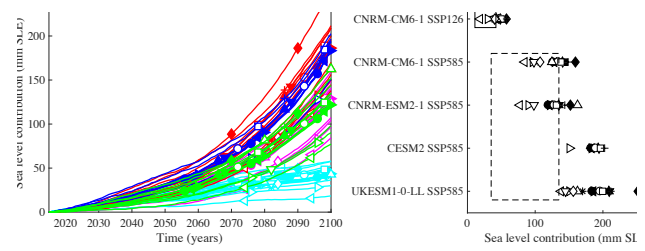

Figure 4. GMSLR contribution from the GrIS to 2100. (a) Time series of contribution between 2015 and 2100 (in $\mathrm{mm}$ ) for whole ice sheet as a function of ice sheet model (symbol) and experiment (see legend) and (b) contribution at 2100. Symbols refer to ice sheet models and are given in Table 2. Boxes in panel (b) refers to ranges from equivalent CMIP5-forced experiments (see Goelzer et al. (2020b)).

Figure 4 shows projections for the GrIS from the fourteen participating ice-sheet models for each CMIP6-forced experiment along with ranges from the equivalent CMIP5forced experiments (Goelzer et al., 2020b). Projected GMSLR is either at the upper end of the CMIP5-forced range or well above it. Indeed, both CESM2 and UKESM1-0-LLbased projections do not overlap with the CMIP5 range at all and, in the latter case, are almost double. In contrast to the AIS, projections for SSP126 (one ESM) are considerably lower than SSP585 (four ESMs) such that the ranges for CMIP6 SSP126 and SSP585 do not overlap. The trajectory of GMSLR associated with SSP126 starts to become distinct from SSP585 around 2060 but is not entirely separate until 2090. There is also a suggestion that GMSLR may stabilise (or at least increase at a far reduced rate) beyond 2100 for SSP126, which is certainly not the case for SSP585. 


\section{Discussion}

We present the first comparison between CMIP5 and CMIP6-based projections of the contribution of ice sheets to future GMSLR up to 2100. This comparison is particularly interesting because many CMIP6 ESMs have higher climate sensitivity than their CMIP5 counterparts (Forster et al., 2019; Meehl et al., 2020) and their projections of future global warming are therefore higher. The comparison is hampered by the use of a relatively small ensemble of available CMIP6 ESMs, which are all at the upper end of CMIP6's range of climate sensitivity.

The comparison between CMIP5 and CMIP6 is markedly different for the two ice sheets, reflecting the very different ways in which the ice sheets are impacted by and respond to changes in the global climate system. For the GrIS, our results suggest that GMSLR contributions under CMIP6 are much higher than for CMIP5 perhaps by a factor of two. They also suggest a significant difference between SSP585 and SSP126, with the former experiencing accelerating rates of mass loss in marked contrast to the tendency towards stabilization of the latter.

Goelzer et al. (2020b) demonstrate that in excess of $80 \%$ of GrIS' contribution to GMSLR can be explained by changing SMB (primarily by surface melt and subsequent runoff), which is mostly controlled by atmospheric processes. The link between global warming and mass loss from the ice sheet is therefore fairly direct and a strong relationship between the two should be expected. The higher climate sensitivity of the sampled CMIP6 ESMs will therefore manifest itself as a larger GMSLR contribution in comparison to CMIP5. It should also be noted that for GrIS (in contrast to AIS), global warming is likely to favour increased mass loss by both atmospheric (i.e, SMB) and ocean forcing (i.e., discharge). However it appears that, at least within the ISMIP6 experimental design, ocean forcing plays a secondary role to the atmosphere.

For AIS, our results up to 2100 suggest little difference between CMIP6 and CMIP5forced projections. This reflects the more complex interactions between this ice sheet and the global climate system. Global warming is likely to favour mass loss through changes in discharge resulting from increased ocean thermal forcing; however, the opposite is expected of the atmospheric forcing where warming is likely to favour mass gain (as a consequence of increased snow accumulation). The higher climate sensitivity of the sampled CMIP6 ESMs is therefore associated with both increased mass gain (snowfall) and mass loss (discharge) resulting in little net change in comparison to CMIP5 forcing. The complicated regional nature of interactions between ocean thermal forcing and AIS' discharge (e.g., Jenkins et al., 2018) is also likely to weaken any link between global warming and AIS mass loss.

The experimental design of the CMIP6-forced experiments reported here does not include the fracture and collapse of AIS' floating ice shelves resulting from meltwater ponding due to significant atmospheric warming (Trusel et al., 2015). This process has been cited as a necessary precursor to rapid ice loss by the retreat of marine ice cliffs (DeConto \& Pollard, 2016). As ice shelf fracture was included in the CMIP5-forced experiments, an initial assessment can be made by comparing the amount of atmospheric warming projected to occur under CMIP5 and CMIP6. Figure 1 suggests that CMIP6 ESMs lie close to or above the maximum CMIP5 surface temperature warming for AIS. For CMIP5 forcing, this process is limited to the Antarctic Peninsula and areas around George VI ice shelf and Totten glacier and its impact on GMSLR is $\sim 28 \mathrm{~mm}$ (Seroussi et al., 2020). Ice-shelf fracture and associated processes may therefore be important under some CMIP6 forcing, in particular for CESM2 and UKESM1-0-LL, and likely be enhanced beyond 2100. 


\section{Acknowledgments}

The data analysed in this paper are from available on Zenodo with digital object identifier https://doi.org/10.5281/zenodo.4498331. We would like to thank the Climate and Cryosphere (CliC) project for providing support for ISMIP6 through the sponsorship of workshops and hosting the ISMIP6 website. We acknowledge the University at Buffalo for their help with ISMIP6 data distribution, and the multiple agencies that support CMIP5, CMIP6 and the ESGF. This is ISMIP6 contribution number 12. This project received funding from the European Unions Horizon 2020 research and innovation programme under grant agreement No 869304, PROTECT contribution number 4.

\section{References}

Barthel, A., Agosta, C., Little, C. M., Hatterman, T., Jourdain, N. C., Goelzer, H., ... Bracegirdle, T. J. (2020). Cmip5 model selection for ismip6 ice sheet model forcing: Greenland and antarctica. The Cryosphere, 14, 855-879. doi: 10.5194/tc-14-855-2020

DeConto, R., \& Pollard, D. (2016). Contribution of antarctica to past and future sea-level rise. Nature, 531(7596), 591-597. doi: 10.1038/nature17145

Eyring, V., Bony, S., Meehl, G. A., Senior, C. A., Stevens, B., Stouffer, R. J., \& Taylor, K. E. (2016). Overview of the coupled model intercomparison project phase 6 (cmip6) experimental design and organization. Geosci. Model Dev., 9(5), 1937-1958. doi: 10.5194/gmd-9-1937-2016

Favier, L., Jourdain, N. C., Jenkins, A., Merino, N., Durand, G., Gagliardini, O., ... Mathiot, P. (2019). Assessment of sub-shelf melting parameterisations using the oceanice-sheet coupled model nemo(v3.6)elmer/ice(v8.3). Geosci. Model Dev., 12, 22552283. doi: 10.5194/gmd-12-2255-2019

Fettweis, X., Franco, B., Tedesco, M., van Angelen, J. H., Lenaerts, J. T. M., van den Broeke, M. R., \& Galle, H. (2013). Estimating the greenland ice sheet surface mass balance contribution to future sea level rise using the regional atmospheric climate model mar. The Cryosphere, 7(2), 469-489. doi: 10.5194/tc-7-469-2013

Flato, G., Marotzke, J., Abiodun, B., Braconnot, P., Chou, S., Collins, W., ... Rummukainen, M. (2013). Evaluation of climate models. In T. Stocker et al. (Eds.), Climate change 2013: The physical science basis. contribution of working group $i$ to the fifth assessment report of the intergovernmental panel on climate change (p. 741866). Cambridge, United Kingdom and New York, NY, USA: Cambridge University Press. doi: 10.1017/CBO9781107415324.020

Forster, P., Maycock, A., McKenna, C., \& Smith, C. (2019). Latest climate models confirm need for urgent mitigation. Nature Climate Change.

Goelzer, H., Noel, B., Edwards, T. L., Fettweis, X., Gregory, J. M., Lipscomb, W. H., .. van den Broeke, M. R. (2020a). Remapping of greenland ice sheet surface mass balance anomalies for large ensemble sea-level change projections. The Cryosphere, 14(6), 1747-1762. doi: 10.5194/tc-14-1747-2020

Goelzer, H., Nowicki, S., Payne, A., Larour, E., Seroussi, H., Lipscomb, W., ... van den Broeke, M. (2020b). The future sea-level contribution of the greenland ice sheet: a multi-model ensemble study of ismip6. The Cryosphere, 14(9), 3071-3096. doi: 10.5194/tc-14-3071-2020

IPCC. (2013). Annex iii: Glossary. In T. Stocker et al. (Eds.), Climate change 2013: The physical science basis. contribution of working group $i$ to the fifth assessment report of the intergovernmental panel on climate change (p. 14471466). Cambridge, United Kingdom and New York, NY, USA: Cambridge University Press. doi: 10.1017/CBO9781107415324.031

Jenkins, A., Shoosmith, D., Dutrieux, P., Jacobs, T. W., Stan Kim, Lee, S. H., Ha, H. K., \& Stammerjohn, S. (2018). West antarctic ice sheet retreat in the amundsen sea driven by decadal oceanic variability. Nature Geoscience, 
11 (10), 733-738. doi: 10.1038/s41561-018-0207-4

Jourdain, N., Asay-Davis, X., Hattermann, T., Straneo, F., Seroussi, H., Little, C., \& Nowicki, S. (2020). A protocol for calculating basal melt rates in the ismip6 antarctic ice sheet projections. The Cryosphere, 14(9), 3111-3134. doi: 10.5194/tc-14-3111-2020

Meehl, G., Senior, C., Eyring, V., Flato, G., Lamarque, J.-F., Stoffer, R., \& Schlund, M. (2020). Context for interpreting equilibrium climate sensitivity and transient climate response from the cmip6 earth system models. Science Advances, 6(26). doi: 10.1126/sciadv.aba1981

Nowicki, S., Goelzer, H., Seroussi, H., Payne, A. J., Lipscomb, W. H., Abe-Ouchi, A., ... van de Wal, R. (2020). Experimental protocol for sea level projections from ismip6 standalone ice sheet models. The Cryosphere, 14 (7), 2331-2368. doi: 10.5194/tc-14-2331-2020

Nowicki, S., Payne, A., Larour, E., Seroussi, H., Goelzer, H., Lipscomb, W., ... Shepherd, A. (2016). Ice sheet model intercomparison project (ismip6) contribution to cmip6. Geoscientific Model Development, 9(12), 4521-4545. doi: 10.5194/gmd-9-4521-2016

Schoof, C. (2007). Ice sheet grounding line dynamics: Steady states, stability, and hysteresis. Journal of Geophysical Research-Earth Surface, 112(F3). doi: 10 .1029/2006JF000664

Seroussi, H., Nowicki, S., Payne, A. J., Goelzer, H., Lipscomb, W. H., Abe-Ouchi, A., ... Zwinger, T. (2020). Ismip6 antarctica: a multi-model ensemble of the antarctic ice sheet evolution over the 21st century. The Cryosphere, 14 (9), 3033-3070. doi: 10.5194/tc-14-3033-2020

Slater, D. A., Felikson, D., Straneo, F., Goelzer, H., Little, C., Morlighem, M., ... Nowicki, S. (2020). 21st century ocean forcing of the greenland ice sheet for modeling of sea level contribution. The Cryosphere, 14(3), 985-1008. doi: 10.5194/tc-14-985-2020

Slater, D. A., Straneo, F., Felikson, D., Little, C. M., Goelzer, H., Fettweis, X., \& Holte, J. (2019). Estimating greenland tidewater glacier retreat driven by submarine melting. The Cryosphere, 13(9), 2489-2509. doi: 10.5194/tc-13-2489-2019

Taylor, K., Stouffer, R., \& Meehl, G. (2012). An overview of cmip5 and the experiemnt design. Bulletin of the American Meteorological Society, 93(4), 485498. doi: 10.1175/BAMS-D-11-00094.1

Trusel, L. D., Frey, K. E., Das, S. B., Karnauskas, K. B., Kuipers Munneke, P., van Meijgaard, E., \& van den Broeke, M. R. (2015). Divergent trajectories of antarctic surface melt under two twenty-first-century climate scenarios. Nature Geoscience, 8(12), 927-932. doi: 10.1038/ngeo2563 